\title{
The Impact of Preparedness in Defying COVID-19 Pandemic Expectations in the Lower Mekong Region: A Case Study
}

\author{
Andrew Corwin, ${ }^{1 \star}$ Tanarak Plipat, ${ }^{2}$ Rattanaxay Phetsouvanh, ${ }^{3}$ Mayfong Mayxay, ${ }^{4,5}$ Phonepadith Xangsayarath, ${ }^{6}$ \\ Le Thi Quynh Mai, ${ }^{7}$ Sophal Oum, ${ }^{8}$ and Md Abdul Kuddus ${ }^{9,10}$ \\ ${ }^{1}$ Global Health Program, Faculty of Public Health, Thammasat University, Bangkok, Thailand; ${ }^{2}$ Office of the Deputy-Director General, Department \\ of Disease Control, Ministry of Public Health, Bangkok, Thailand; ${ }^{3}$ Office of Director-General, Department of Communicable Disease Control, \\ Ministry of Health, Vientiane, Lao PDR; ${ }^{4}$ Institute of Research and Education Development (IRED), University of Health Sciences, Vientiane, Lao \\ PDR; ${ }^{5}$ Lao-Oxford-Mahosot Hospital-Welcome Trust Research Unit (LOMWRU), Mahosot Hospital, Vientiane, Lao PDR; ${ }^{6}$ National Center for \\ Laboratory and Epidemiology (NCLE), Ministry of Health, Vientiane, Laos PDR; ${ }^{7}$ National Institute of Hygiene and Epidemiology (NIHE), Hanoi, Vietnam; \\ ${ }^{8}$ University of Health Sciences, Phnom Penh, Cambodia; ${ }^{9}$ Department of Mathematics, University of Rajshahi, Rajshahi, Bangladesh; ${ }^{10}$ Australian Institute \\ of Tropical Health and Medicine, James Cook University, Townsville, Australia
}

\begin{abstract}
Dire COVID-19 expectations in the Lower Mekong Region (LMR) can be understood as Cambodia, the Lao PDR, Myanmar, Thailand, and Vietnam have stared down a succession of emerging infectious disease (EID) threats from neighboring China. Predictions that the LMR would be overwhelmed by a coming COVID-19 tsunami were felt well before the spread of the COVID-19 pandemic had been declared. And yet, the LMR, excepting Myanmar, has proved surprisingly resilient in keeping COVID-19 contained to mostly sporadic cases. Cumulative case rates (per one million population) for the LMR, including or excluding Myanmar, from January 1 to October 31 2020, are 1,184 and 237, respectively. More telling are the cumulative rates of COVID-19-attributable deaths for the same period of time, 28 per million with and six without Myanmar. Graphics demonstrate a flattening of pandemic curves in the LMR, minus Myanmar, after managing temporally and spatially isolated spikes in case counts, with negligible follow-on community spread. The comparable success of the LMR in averting pandemic disaster can likely be attributed to years of preparedness investments, triggered by avian influenza $A(H 5 N 1)$. Capacity building initiatives applied to COVID-19 containment included virological (influenzadriven) surveillance, laboratory diagnostics, field epidemiology training, and vaccine preparation. The notable achievement of the LMR in averting COVID-19 disaster through to October 31, 2020 can likely be credited to these preparedness measures.
\end{abstract}

\section{INTRODUCTION}

First reported from Wuhan China on December 31, 2019 through the WHO, more than 36 million COVID-19 cases and more than one million deaths have since been recorded globally. ${ }^{1,2}$ Early predictive estimates projected exponential growth in the number of new COVID-19 cases resulting from silent importations via asymptomatic carriers, with the likelihood of overwhelming the Lower Mekong Region (LMR) along China's southern flank, with Myanmar, the Lao PDR, and Vietnam buttressed up against the border (Figure 1). ${ }^{3-6}$

Thailand, followed by Vietnam, has consistently ranked as top outbound travel destinations from China; Thailand alone registered more than 10 million such visits in $2018 .^{7-9}$ This pattern of travel preference which extended to Cambodia, Myanmar, and the Lao PDR continued unabated through the early phase of the impending pandemic (when still classified by the WHO as a Health Emergency of International Concern), with restrictions targeting China put-in-place after COVID-19 was already well on the move. Control measures included border closure on January 28 and suspension of "visas-uponarrival" on February 2 by the Lao PDR, suspension of "visaupon-arrival" on March 11 by Thailand, suspension of Visa Issuance on February 1, and cancellation of all inbound and outbound flights on February 2 by Vietnam. ${ }^{10}$ Irrespectively, there was much to fear in the LMR because COVID-19 had at least a 2-month head start on actions taken to mitigate spread from China to the north.

*Address correspondence to Andrew Corwin, Faculty of Public Health, Thammasat University, Rangsit Campus, Khlong 1, Khlong Luang, Pathumthani 12121, Thailand. E-mail: corwinal2e@yahoo.com
East Asia has proved fertile ground in the emergence of pandemic threats for decades. The LMR has been left to fend against a succession of emerging infectious diseases (EIDs) of zoonotic origin that include SARS virus and avian influenzas (Als) A (H5N1) and A (H5N7) emanating from China; and Nipah virus from Malaysia. ${ }^{11,12}$

Conditions in the LMR favoring pandemic occurrence have been influenced by 1) near proximity to China; 2) agrariandominated economies characterized by animal-to-animal and animal-to-human interface opportunities, which include backyard animal production, wet market exchanges, intensive large-scale animal breeding practices, hunting and consumption of wild game, and non-sanctioned (exotic) animal trade; and 3) significant cross-border flows of migrants, much of which was unfettered. ${ }^{12-15}$ Notwithstanding such prevailing conditions favoring early spread to and within the LMR, and heightened sensitivity to the threat posed with recognition of the first COVID-19 case registered outside of China on January $13,2020,{ }^{2}$ in Thailand, the predicted doom-and-gloom scenarios have not been borne out as reflected in the numbers. ${ }^{1,12}$

The purpose of this case study was 2-fold, first, to quantifiably validate (from January through October 2020) the COVID-19 success of the LMR with respect to COVID-19 containment and second, highlight the role of EID preparedness through capacity building investments, the benefits of which are now being realized against a COVID-19 contagion. In addition, observations made from a thorough review of the available literature were intended to show how the LMR, having faced off a succession of EID threats spanning two decades, took to preparedness with a vengeance; 


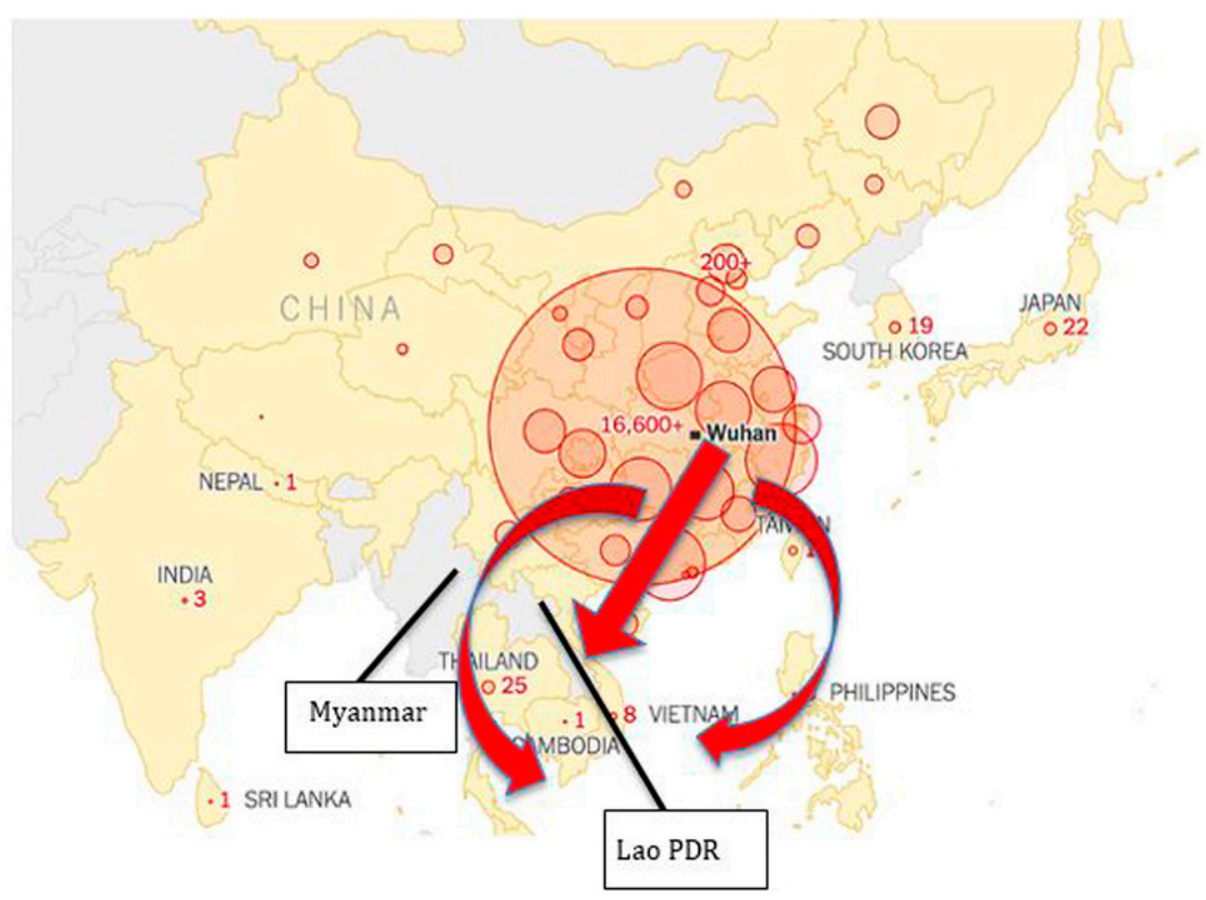

FIGURE 1. Snapshot of early COVID-19 spread in Asia, with numbers reflecting country cumulative case counts, as of February 3, 2020; https:// www.nytimes.com/2020/02/03/world/asia/coronavirus-china.html. This figure appears in color at www.ajtmh.org.

these findings were used to examine the likely positive impact in doing so.

\section{METHODS}

This case study relied on data extraction from a sourced COVID-19 case generating dashboard, as of October 31, 2020. Ministries of Health from the LMR and other selected countries reported case and death counts through the WHO, as mandated by the International Health Regulations for the purpose of comparative and trend analysis. Data were obtained from the following sources:

\section{European Union Open Data Portal}

(https://data.europa.eu/euodp/en/data/dataset/covid-19coronavirus-data); and

\section{Worldometer, World Population (https://www.worldometers.info/ world-population/).}

Comparative analysis was broadened beyond the LMR to include countries and territories selected to provide for some global (geographical) representation, again, with rates based on cumulative case counts through October 2020, although emphasis was placed on the Western Pacific Rim to make analysis more geographically compatible with the LMR. Graphic trend analysis was performed for the five countries that comprise the LMR for the period of January 1, to October 31, 2020, using MATLAB programming language to explore the dynamics of cumulative case counts and incidence rates. All rates were expressed as per one million population. Graphic design incorporated a log scale for presentation of cumulative case counts to provide for improved visual acuity of trend activity, regardless of the absolute number of cases reported.

\section{RESULTS}

Counting cases. The estimated $245,542,882$ persons in the LMR constitute a sizable COVID-19 "risk population." Low cumulative rates of recognized COVID-19 cases and deaths (per million population as of October 31, 2020) in the LMR are in stark contrast to those in many more resource-advantaged countries around the world. In actual case numbers during this time frame, Myanmar stood out as an outlier $(51,496)$, followed by Thailand $(3,834)$, Vietnam $(1,177)$, Cambodia $(290)$, and the Lao PDR (24). Overall rates for the LMR, with and without Myanmar, were 1,184 cases (and 28 deaths) and 237 cases (and six deaths), respectively. The LMR success in mitigating the human COVID-19 toll, notwithstanding Myanmar, is made even more evident by comparisons with many other countries around the world, where much higher rates were seen, especially outside of Asia (Table 1).

Figures 2 and 3 reflect COVID-19 trends for the LMR. Early introduction of cases did not result in sustained community spread until mid-March, when incidence rates climbed dramatically, Vietnam and Cambodia recorded spikes in new cases but were able to quickly flatten their respective curves, whereas Thailand continued to see cumulative case count increases through April (Figure 2).

Incidence demonstrably seesawed week-to-week in Vietnam and Cambodia from May through July, whereas Thailand's curve flattened out at the beginning of April and remained so through October (Figure 2). For the last 3 months (August through October), the curve for Vietnam, Cambodia, and Thailand remained flat, whereas new case counts in Myanmar have skyrocketed (Figures 2 and 3).

Most striking from the Lao PDR is the paucity of COVID-19 cases graphically on display in Figure 2. Except for a barely perceptible bump up in April, the growth curve has remained stagnant, with no discernable upward trajectory. 
TABLE 1

Cumulative COVID-19 case and death rates, October 31, 2020

\begin{tabular}{|c|c|c|c|c|c|}
\hline Region/country & $\begin{array}{l}\text { Total population } \\
\text { estimates }\end{array}$ & $\begin{array}{l}\text { Cumulative number of } \\
\text { cases }\end{array}$ & $\begin{array}{c}\text { Cumulative case rates (per one million } \\
\text { population) }\end{array}$ & $\begin{array}{l}\text { Cumulative number of } \\
\text { deaths }\end{array}$ & $\begin{array}{c}\text { Cumulative death rates (per one million } \\
\text { population) }\end{array}$ \\
\hline \multicolumn{6}{|c|}{ Lower Mekong Region } \\
\hline Cambodia & $16,718,965$ & 284 & 17 & 0 & 0 \\
\hline Lao PDR & $7,275,560$ & 22 & 3 & 0 & 0 \\
\hline Myanmar & $54,409,800$ & 51,363 & 944 & 1,197 & 22 \\
\hline Thailand & $69,799,978$ & 3,839 & 55 & 59 & $<1$ \\
\hline Vietnam & $7,275,560$ & 1,179 & 162 & 36 & 5 \\
\hline \multicolumn{6}{|l|}{ Western Pacific } \\
\hline Australia & $25,598,361$ & 27,569 & 1,077 & 896 & 35 \\
\hline Brunei & 438,877 & 148 & 337 & 3 & 7 \\
\hline China & $1,441,176,476$ & 90,794 & 63 & 4,324 & 3 \\
\hline $\begin{array}{l}\text { French } \\
\quad \text { Polynesia }\end{array}$ & 281,452 & 7,262 & 25,802 & 29 & 103 \\
\hline Indonesia & $274,479,674$ & 407,053 & 1,483 & 13,724 & 50 \\
\hline Japan & $126,346,336$ & 100,445 & 795 & 1769 & 14 \\
\hline Malaysia & $32,502,676$ & 30,910 & 951 & 260 & 8 \\
\hline New Zealand & $4,835,327$ & 1,600 & 331 & 24 & 5 \\
\hline $\begin{array}{c}\text { Papua New } \\
\text { Guinea }\end{array}$ & $9,002,893$ & 585 & 65 & 7 & $<1$ \\
\hline Philippines & $110,065,461$ & 378,955 & 3,443 & 7,154 & 65 \\
\hline Singapore & $5,865,603$ & 58,005 & 9,889 & 29 & 5 \\
\hline South Korea & $51,283,946$ & 26,514 & 517 & 1,487 & 9 \\
\hline Taiwan & $23,831,180$ & 548 & 23 & 7 & $<1$ \\
\hline Timor Leste & $1,326,653$ & 31 & 23 & 0 & 0 \\
\hline \multicolumn{6}{|c|}{ Greater Asia (outside Western Pacific) } \\
\hline Bangladesh & $165,236,639$ & 406,317 & 2,459 & 5,949 & 36 \\
\hline Nepal & $29,136,808$ & 16,462 & 565 & 903 & 31 \\
\hline Qatar & $2,897,135$ & 132,344 & 45,681 & 232 & 80 \\
\hline \multicolumn{6}{|l|}{ Americas } \\
\hline Argentina & $45,334,239$ & $1,157,156$ & 25,525 & 30,782 & 679 \\
\hline Bolivia & $11,725,880$ & 141,625 & 12,078 & 8,712 & 743 \\
\hline Canada & $37,852,693$ & 231,999 & 6,129 & 10,107 & 267 \\
\hline Cuba & $11,324,280$ & 6,806 & 601 & 125 & 11 \\
\hline Peru & $33,124,270$ & 900,185 & 27,176 & 34,416 & 1,039 \\
\hline United States & $331,653,357$ & $9,047,172$ & 27,279 & 229,836 & 693 \\
\hline \multicolumn{6}{|l|}{ Europe } \\
\hline Netherlands & $17,147,638$ & 340,981 & 19,885 & 7,339 & 428 \\
\hline Spain & $46,760,889$ & $1,187,867$ & 25,403 & 39,699 & 849 \\
\hline \multicolumn{6}{|l|}{ Africa } \\
\hline Kenya & $53,771,296$ & 52,588 & 978 & 968 & 18 \\
\hline South Africa & $59,557,257$ & 723,680 & 12,151 & 19,237 & 323 \\
\hline
\end{tabular}

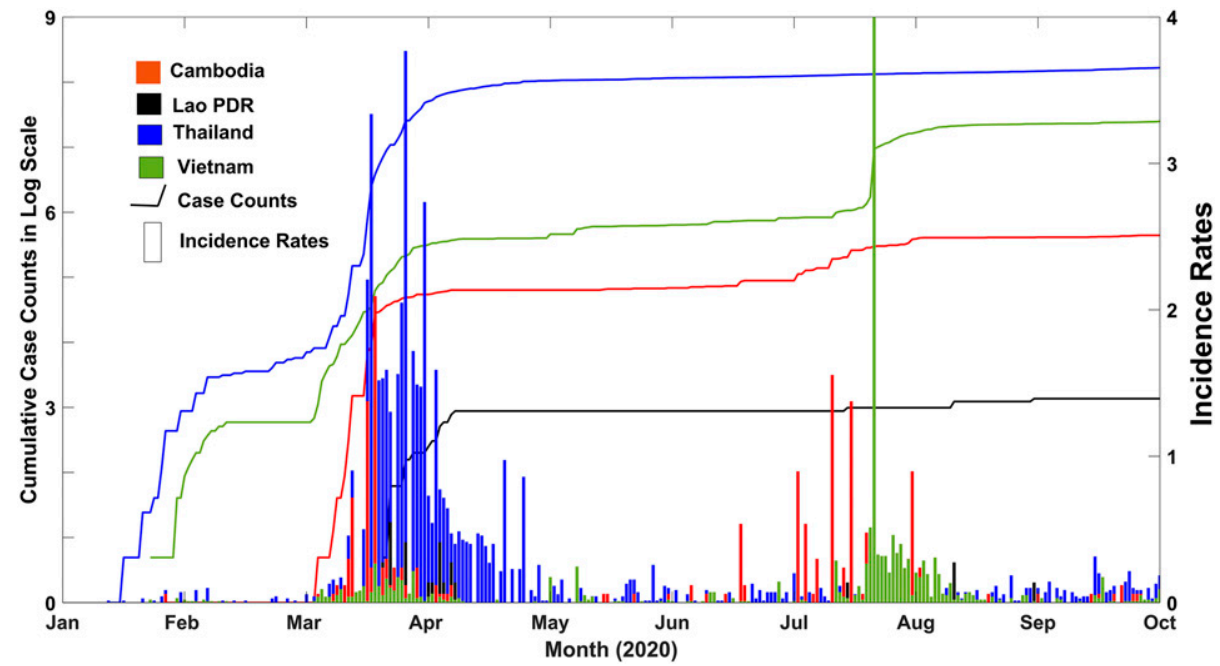

FIGURE 2. COVID-19 case counts (expressed as Logarithm [Log] values) and incidence rates (per one million population) in the Lower Mekong Region, excepting for Myanmar, January through October 2020. 


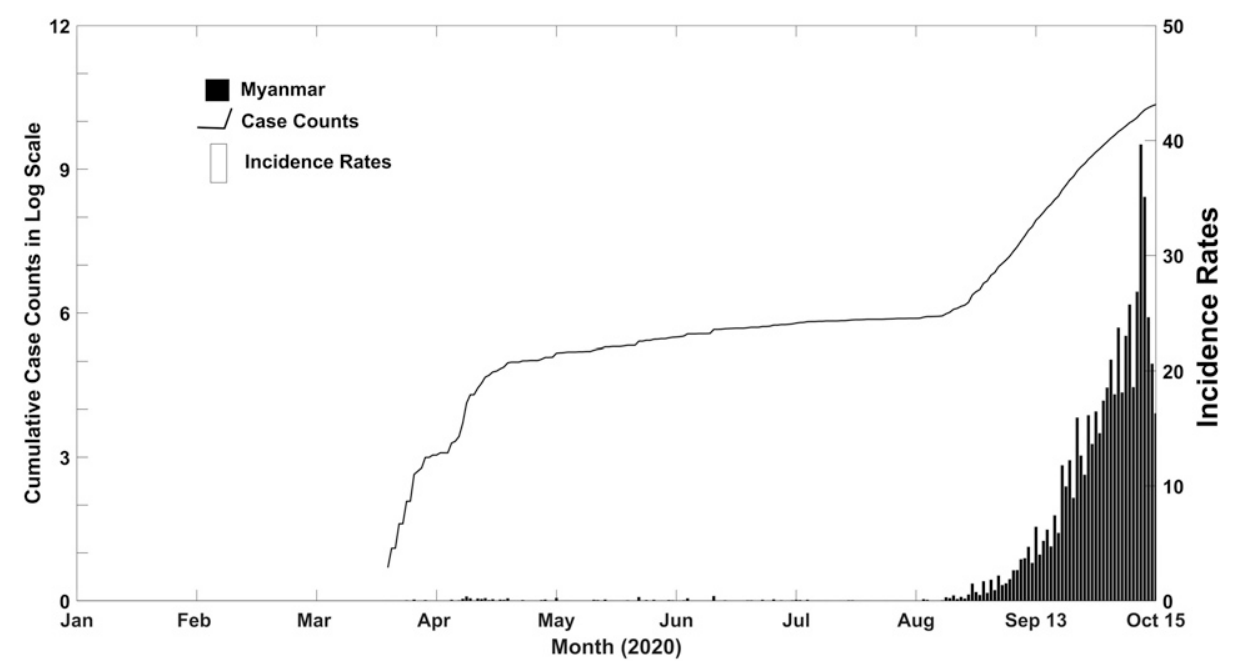

FIGURE 3. COVID-19 case counts (expressed as Logarithm [Log] values) and incidence rates (per one million population) in Myanmar, January through October 2020.

Other sourced findings reinforce trends gleaned from Figure 2. In the Lao PDR, there has been no evidence of community-acquired infections since April 12, whereas Thailand went 100 days (May 24 to August 26, 2020) and has since registered only two indigenous cases through October, with latter infections in both countries attributed to returnees and captured through strictly regulated quarantining. ${ }^{1,13,14}$ In Vietnam, there had been no local transmission for almost 100 days, until July 25, when a large case cluster fueled by community spread was recognized in Danang, in Central Vietnam. This outbreak was quickly brought under control, with no new cases nationwide, from September 4, onward. ${ }^{1,13,15,16}$ Finally, Cambodia's notable success in limiting COVID-19 transmission to sporadic cases was ascribed by the WHO to preparedness. ${ }^{17,18}$

Preparedness. Amid fears triggered by the emergence (first recognized from China) of Al A (H5N1) influenza, countries in the WHO Western Pacific Regional Office/South East Asia Regional Office spheres embarked on an initiative to establish (in 2005) national pandemic detection and response capabilities under the rubric of the WHO's Asia Pacific Strategy for Emerging Diseases and Public Health Emergencies. ${ }^{19}$ The LMR as a whole aggressively took up the "call to arms," fueled not only by the "bird" flu Health Emergency of International Concern but by the recent memory of prior pandemic threats like Nipah virus and SARS, both from the immediate neighborhood, Malaysia and China, respectively. ${ }^{11}$

The LMR leadership expressed resolve by steering investments into building credible detection and response capabilities in the face of the pandemic imperative, designed to counter merging EID threats. These included 1) laboratory diagnostics; 2) real-time electronically driven outbreak alert systems; 3) virological (influenza-focused) surveillance networks; 4) infection control; 5) field epidemiology training programs (FETP); 6) One Health cooperation and coordination with emphasis between animal and human health sectors, which includes shared training platforms like FETP, information sharing and joint outbreak investigations, and control/mitigation activities; 7) passive surveillance/reporting mechanisms, like toll-free hotline access; 8) risk communication that includes interface with and messaging through civic and social media forums; 9) emergency operation center functions in managing response; 10) simulation exercises and cross-border coordination; 11) vaccine preparedness; and 12) central governmental coordinating entities under the most senior echelons of power to ensure the following: messaging is not confused or contradictory (that the government is speaking with one voice), different ministries are working with and not against each other, multi-sector outreach to private and other sectors like religious and civil society, and for setting national and local policies. ${ }^{20}$ These relatively new preparedness products in the pandemic fighting arsenal have given the LMR a clear advantage, for which the following examples lend credence.

The success of the FETP model adopted by Thailand in 1980 in creating a cadre of professionals with the necessary field experience and skills (e.g., contact tracing) to validate, control, and mitigate outbreaks led to similar initiatives in Vietnam (2007), the Lao PDR (2009), Cambodia (2011), and latecomer Myanmar (2018). ${ }^{20-24}$ The Lao FETP now boasts an impressive alumni network of 87 graduates working across the country enabling a coordinated nationwide response to the COVID-29 crises $^{20}$

Pandemic simulation exercises established response options and a capable workforce from multi-sectors, nationally and locally, who trained and practiced together. These activities included cross-border exchanges during non-pandemic times. ${ }^{25}$ This enables the LMR to successfully reabsorb thousands of returning migrant workers across national and international land borders, without adding to the potential spread of COVID-19. ${ }^{26}$

Virological influenza surveillance in the LMR is designed to monitor trends, including the emergence of novel subtypes, for example, Al A (H7N9). ${ }^{11,27}$ This requires complementary molecular diagnostic prowess, cited as an essential ingredient to pandemic preparedness. ${ }^{28}$ The same surveillance networks and molecular testing platforms, tweaked and expanded on, are proving invaluable in capturing COVID-19 cases. Indeed, the value of influenza (virological) surveillance in the Lao PDR was not fully realized until the COVID-19 pandemic (as cited by the Vice Minister of Health, at the Annual National Influenza Surveillance Meeting, 24-26 September 2020). 
The imperative of vaccine preparedness is not lost, given a global rush to rollout a COVID-19 vaccine. ${ }^{29}$ The Lao PDR became the first lower-middle-income country to introduce seasonal influenza vaccine into their national immunization portfolio following the successful deployment of swine influenza A (H1N1) pdm09 vaccine in 2010, enabling sustained preparedness during interpandemic periods through annual immunization campaigns. ${ }^{30}$

Meanwhile, Thailand and Vietnam following Indonesia's lead, put into context by the $\mathrm{Al}$ A $(\mathrm{H} 5 \mathrm{~N} 1)$ virus sharing debacle, embarked on respective manufacturing enterprises to produce seasonal influenza vaccine during interpandemic periods: a capacity that can readily be converted to pandemic vaccine production. ${ }^{31-34}$ This capability is enabling Thailand to move forward with production arrangements of AstraZeneca's candidate COVID-19 vaccine for domestic use. ${ }^{35}$

\section{DISCUSSION}

Skepticism has been raised regarding the veracity of surveillance findings in light of lower-than-expected COVID-19 case counts in the LMR. Yet the systems so relied on in tracking influenza trends, including incipient recognition of $A$ (H1N1) pdm09, are proving equally capable of capturing hospitalized COVID-19 infections and providing reliable national laboratory test results.

In the absence of data denoting severity and hospitalizations, death counts were applied to the analysis in attempting to smooth out the impact of testing variability for making COVID-19 country comparisons as severe and/or hospitalized cases are more likely to be tested and therefore serve as useful surrogate indictors.

Whereas expressed rates provide a snapshot of infections worldwide for comparative analysis, COVID-19 counts are largely a function of testing. In the LMR as elsewhere, the veracity of country data in reflecting "true infections" is suspect, owing to the rapidly changing dynamics influencing case findings: diagnostic technology (e.g., accuracy, cost, and laboratory capacity), epidemiology (e.g., current incidence trends, transmissibility, and virulence), and accessibility (affordability, availability, and convenience). ${ }^{12}$

Furthermore, demographics and health status associated with COVID-19 case severity may impact the likelihood of being tested. ${ }^{36,37}$ This poses challenges to meaningful comparative data interpretation.

And yet the COVID-19 scenario being played out in the LMR, excepting of Myanmar, defies earlier expectations. The evidence, both anecdotal and observational, corroborates datadriven findings. Importantly, that COVID-19 cases have not found their way into an all-pervasive social media in the LMR adds credence to the premise that speculative doom-andgloom predictions were miscalculated and proved wrong (Figure 2). ${ }^{6,13,38}$ Notwithstanding the evidence, there is scant reflection in the scientific literature to this aberration, attesting to the notable success of the LMR in stemming local transmission.

The importance credited to preparedness no matter the pandemic scenario cannot be overstated. ${ }^{39,40}$ Anticipating and adapting to rapidly changing conditions with wellpracticed control and mitigation actions, relying on both systems and well-versed workforce already in place, are critical to containment efforts. The positive impact of preparedness reflected in COVID-19 trends has been demonstrated in multicountry analysis. ${ }^{41}$ Correspondingly, preparation is cited as the lesson taken from Vietnam's favorable COVID-19 experience. ${ }^{42}$ In the LMR, a shared vulnerability to EIDs of pandemic potential energized this process of strengthening capacity to manage such threats.

There are many likely influences other than preparedness that contributed to the LMR success in containing COVID-19. Certainly, the political, cultural, religious, and social complexities of the LMR should be taken into consideration relative to the overall role of preparedness. Yet the ethnic diversity within and between the respective countries makes nearly impossible broad stroke characterizations as related to COVID-19 management. The Lao PDR provides one such example of the ethnic heterogeneity found throughout the LMR. The country's 49 recognized ethnicities composed of more than 160 ethnic groups, speaking an estimated 82 distinct languages and dialects, highlights the folly in lumping the peoples of the LMR into any single stereotypic grouping. ${ }^{43}$ Furthermore, political nuances that accommodate disparate cultural, religious, and societal norms make attempts to frame the LMR as a homogenous universe in proportioning the COVID-19 impact an exercise of conjecture biased by perspective. Rather, it is preparedness, universally and yet uniquely applied throughout the LMR with exception of Myanmar, fueled by the shared EID experiences, where causal relationships can be validated.

The inclusion of Myanmar in our analysis highlights the importance of preparedness relative to COVID-19 outcomes. Myanmar's slow pace in adopting a robust preparedness agenda at least partially accounts for the explosion of COVID19 cases (Figure 3); conversely, the LMR countries which undertook ambitious EID preparations have been able to curtail community spread to only a few clusters that were quickly contained, as of 31 October 2020.

In conclusion, early predictions in 2006 proved prophetic in recognizing the pandemic risk in the context of $\mathrm{Al} A(\mathrm{H} 5 \mathrm{~N} 1)$ spread to the LMR, in the absence of preparedness. ${ }^{11}$ Whereas the LMR faced the AI A (H5N1) threat from a severe deficit in detection and response capabilities, such proved not the case with COVID-19. ${ }^{44}$ The advances made in the years following the $\mathrm{Al} \mathrm{A}(\mathrm{H} 5 \mathrm{~N} 1)$ scare likely created the wherewithal to take on COVID-19, as attested to in the analytics and observations presented. As such, lessons learned from the LMR following years of sustained investments in preparedness would be well applied elsewhere in planning ahead for the next, post-COVID-19, pandemic.

Received November 23, 2020. Accepted for publication January 6, 2021.

Published online January 28, 2021.

Acknowledgments: The American Society of Tropical Medicine and Hygiene has waived the Open Access fee for this article due to the ongoing COVID-19 pandemic and has assisted with publication expenses.

Authors' addresses: Andrew Corwin, Faculty of Public Health, Thammasat University, Bangkok, Thailand, E-mail: corwinal2e@ yahoo.com. Tanarak Plipat, Department of Disease Control, Ministry of Public Health, Bangkok, Thailand, E-mail: kepidem@gmail.com. Rattanaxay Phetsouvanh, Department of Communicable Disease Control, Ministry of Health, Vientiane, Lao PDR, E-mail: rattanaxay@ gmail.com. Mayfong Mayxay, Institute of Research and Education 
Development (IRED), University of Health Sciences, Vientiane, Lao PDR, E-mail: mayfong@tropmedres.ac. Phonepadith Xangsayarath, National Center for Laboratory and Epidemiology (NCLE), Ministry of Health, Vientiane, Lao PDR, E-mail: phonepadithxangsayarath@ gmail.com. Le Thi Quynh Mai, National Institute of Hygiene and Epidemiology (NIHE), Hanoi, Vietnam, E-mail: Itqm@nihe.org.vn. Sophal Oum, University of Health Sciences, Phnom Penh, Cambodia, E-mail: sophal_oum@yahoo.com. Md Abdul Kuddus, Department of Mathematics, University of Rajshahi, Rajshahi, Bangladesh, E-mail: mdabdul.kuddus@my.jcu.edu.au.

This is an open-access article distributed under the terms of the Creative Commons Attribution (CC-BY) License, which permits unrestricted use, distribution, and reproduction in any medium, provided the original author and source are credited.

\section{REFERENCES}

1. WHO, 2020. Coronavirus Disease (COVID-19) Dashboard, 2,3 and 11. Available at: https://covid19.who.int/table. Accessed April 27, 2020.

2. WHO, 2020. Archived: WHO Timeline-COVID-19. Available at: https://www.who.int/news-room/detail/27-04-2020-whotimeline---covid-19. Accessed April 27, 2020.

3. Pinotti F, Di Domenico L, Ortega E, Mancastroppa M, Pullano G, Valdano E, Boëlle PY, Poletto C, Colizza V, 2020. Tracing and analysis of 288 early SARS-CoV-2 infections outside China: a modeling study. PLoS Med 17: e1003193.

4. Phelan AL, Katz R, Gostin LO, 2020. The novel coronavirus originating in Wuhan, China: challenges for global health governance. JAMA 323: 709-710.

5. Du Z, Wang L, Cauchemez S, Xu X, Wang X, Cowling BJ, Meyers LA, 2020. Risk for transportation of coronavirus disease from Wuhan to other cities in China. Emerg Infect Dis 26: 1049-1052.

6. TIME, 2020. A Silent Epidemic? Experts Fear the Coronavirus is Spreading Undetected in Southeast Asia. Available at: https:// time.com/5792180/southeast-asia-undetected-coronavirus/. Accessed February 28, 2020.

7. Ma Y, 2020. Most Popular Destinations Countries Among Outbound Tourists from China 2018. Available at: https:// www.statista.com/statistics/978124/china-leading-destinationcountries-based-on-tourism-popularity-index/. Accesssed June 3, 2020.

8. Travel China Guide, 2020. China Tourism Facts and Figures 2018. Available at: https://www.travelchinaguide.com/ tourism/2018statistics/. Accessed January 20, 2020.

9. Changyong R, 2019. Thailand Tourism Highlights for 2018. Available at: https://www.thailand-business-news.com/ tourism/70867-thailand-tourism-highlights-for-2018.html. Accessed September 21, 2020.

10. Kiernan S, DeVita M, 2020. Travel Restrictions on China Due to COVID-19; Think Global Health, Council on Foreign Relations. Available at: https://www.thinkglobalhealth.org/article/travelrestrictions-china-due-covid-19. Accessed April 6, 2020.

11. Fauci AS, 2006. Pandemic influenza threat and preparedness. Emerg Infect Dis 12: 73-77.

12. Johns Hopkins University, 2020. Data in Motion: Coronavirus Resource Centre. Available at: https://coronavirus.jhu.edu. Accessed October 3, 2020.

13. Martinic MS, 2020. How the Mekong Countries Contained COVID-19. Available at: https://www.theweek.in/news/world/ 2020/09/01/how-the-mekong-countries-contained-covid-19.html. Accessed September 1, 2020.

14. Lardieri A, 2020. Thailand Reports First Local Case of Coronavirus in 100 Days. Available at: https://www.usnews.com/news/ world-report/articles/2020-09-03/thailand-reports-first-localcase-of-coronavirus-in-100-days. Accessed September 3, 2020.

15. Vuong NM, Le Quyen NT, Tra DT, Do Van T, Tuan NQ, Co DX, Trang NTH, Cuong DD, 2020. The second wave of COVID-19 in a tourist hotspot in Vietnam. J Travel Med taaa174. doi: 10.1093/jtm/taaa174.

16. Thuan N, 2020. International Researchers Praise Success Story of Vietnam in Fighting COVID-19. Available at: https:// vietnamtimes.org.vn/international-researchers-praise-success- story-of-vietnam-in-fighting-covid-19-24699.html. Accessed September 26, 2020.

17. Heng K, 2020. Cambodia Deserves Praise for its COVID-19 Success. Available at: https://www.khmertimeskh.com/50763929/ cambodia-deserves-praise-for-its-covid-19-success/. Accessed September 15, 2020.

18. WHO, 2020. 22 Local COVID-19 Preparedness Is Key to Success; Western Pacific, Cambodia. Available at: https://www.who.int/ cambodia/news/feature-stories/detail/local-covid-19-preparednessis-key-to-success. Accessed September 25, 2020.

19. WHO, 2005. Asia Pacific Strategy for Emerging Diseases and Public Health Emergences Available at: https://iris.wpro.who.int/ bitstream/handle/10665.1/13654/9789290618171-eng.pdf. Accessed November 15, 2020.

20. Phommasack B et al., 2012. Capacity building in response to pandemic influenza threats: Lao PDR case study. Am J Trop Med Hyg 87: 965-971.

21. FETP, 2019. Training Course on International FETP Training for Trainer (IFETP Training for Trainer). Available at: http:// www.interfetpthailand.net/course_index.php?1c092a1b53a7a 471fe7c04735dad699b=training_trainer. Accessed September 9, 2020.

22. CDC, 2020. Thailand FETP Celebrates 40 Years of Training, Mentorship, and Public Health Success. Available at: https:// www.cdc.gov/globalhealth/healthprotection/fetp-40th-anniversary/ stories/thailand-fetp-40.html. Accessed September 8, 2020.

23. Todd $P$ et al., 2020. Emerging COVID-19 Success Story: Vietnam's Commitment to Containment; Example in Global Health. Available at: https://www.exemplars.health/emerging-topics/ epidemic-preparedness-and-response/covid-19/vietnam. Accessed September 12, 2020.

24. CDC, 2020. 28 Recent Graduates of Cambodia's FETP Use Their Frontline Training to Respond to COVID-19. Available at: https://www.cdc.gov/globalhealth/healthprotection/fetp-40thanniversary/stories/cambodia-frontline-covid.html. Accessed July 21, 2020.

25. Moore M, Dausey DJ, 2015. Local cross-border disease surveillance and control: experiences from the Mekong Basin. BMC Res Notes 8: 90.

26. Chandrasekhar S, Inkochasan M, Duigan P, 2020. No One Is Safe, until Everyone Is Safe: Migration and COVID-19 in the Greater Mekong Sub-region; International Organization for Migration, Regional Office for Asia and the Pacific. Available at: https:// covid-19chronicles.cseas.kyoto-u.ac.jp/post-059-html/. Accessed August 24, 2020.

27. Khamphaphongphane B et al., 2013. Epidemiological and virological characteristics of seasonal and pandemic influenza in Lao PDR, 2008-2010. Influenza Other Respir Viruses 7: 304-311.

28. Kelly-Cirino CD et al., 2019. Importance of diagnostics in epidemic and pandemic preparedness. BMJ Glob Health 4: e001179.

29. Wright PF, 2008. Vaccine preparedness-are we ready for the next influenza pandemic? N Engl J Med 358: 2540-2543.

30. Xeuatvongsa $A$ et al., 2015. The Lao experience in deploying influenza $A$ (H1N1) pdm09 vaccine: lessons made relevant in preparing for present day pandemic threats. PLoS One 10: e0121717.

31. Suhardono M, Ugiyadi D, Nurnaeni I, Emelia I, 2011. Establishment of pandemic influenza vaccine production capacity at Bio Farma, Indonesia. Vaccine 29: A22-A25.

32. Pitisuttithum P, Wirachwong P, 2019. A review of epidemic preparedness for influenza through local vaccine production: national security for Thailand. Hum Vaccin Immunother 15: 2440-2445.

33. Thang HV et al., 2018. Safety and immunogenicity of inactivated monovalent influenza $\mathrm{A} / \mathrm{H} 1 \mathrm{~N} 1$ vaccine candidate manufactured in Vietnam. Vaccine 36: 6918-6925.

34. PATH, 2019. 38 Vietnam - Produced Seasonal Influenza Vaccine Licensed for Production and Use. Available at: https:// www.path.org/media-center/vietnam-produced-seasonalinfluenza-vaccine-licensed-production-and-use/. Accessed September 20, 2020.

35. REUTERS, 2020. 39 Thailand to Make, Supply AstraZeneca's Covid-19 Vaccine. Available at: https://www.bangkokpost.com/ 
business/2000995/thailand-to-make-supply-astrazenecascovid-19-vaccine. Accessed October 12, 2020.

36. Richardson S et al., 2020. Presenting characteristics, comorbidities, and outcomes among 5700 patients hospitalized with COVID-19 in the New York City area. JAMA 323: 2052-2059.

37. Yang $\mathrm{J}$ et al., 2020. Prevalence of comorbidities and its effects in patients infected with SARS-CoV-2: a systematic review and meta-analysis. Int J Infect Dis 94: 91-95.

38. Gupta A, 2020. Social Media Trends during and after COVID-19 and what This Means for Brands in Asia. Available at: https:// ada-asia.com/covid19-social-media-trends/. Accessed September 17, 2020.

39. Osterholm MT, 2005. Preparing for the next pandemic. $N$ Engl $J$ Med 352: 1839-1842.
40. Lee VJ, Aguilera X, Heymann D, Wilder-Smith A, 2020. Preparedness for emerging epidemic threats: a Lancet infectious diseases commission. Lancet Infect Dis 20: 17-19.

41. Chaudhry R, Dranitsaris G, Mubashir T, Bartoszko J, Riazi S, 2020. A country level analysis measuring the impact of government actions, country preparedness and socioeconomic factors on COVID-19 mortality and related health outcomes. EClinicalMedicine 25: 100464

42. Quach HL, Thi NAH, 2020. COVID-19 in Vietnam: a lesson of prepreparation. J Clin Virol 127: 104379.

43. Migiro G, 2019. What Is the Ethnic Composition of Laos. Available at: https://www.worldatlas.com/articles/what-is-the-ethniccomposition-of-laos.html. Accessed January 4, 2021.

44. Coker R, Mounier-Jack S, 2006. Pandemic influenza preparedness in the Asia-Pacific region. Lancet 368: 886-889. 